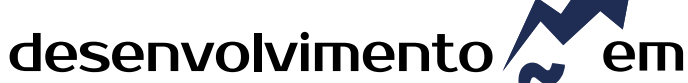 QUESTAOO
}

\section{A PANDEMIA DE COVID-19 E OS IMPACTOS NO SETOR SUPERMERCADISTA: Uma Análise do Panorama de um Município de Minas Gerais}

\author{
http://dx.doi.org/10.21527/2237-6453.2021.56.11836
}

Recebido em: $11 / 12 / 2020$

Aceito em: 13/5/2021

Gabriella Baccarini de Carvalho, ${ }^{1}$ Wellington Tavares ${ }^{2}$

\begin{abstract}
RESUMO
O estado de emergência higiênico-sanitário que a Covid-19 provocou no mundo gerou alterações na mobilidade, na renda e no estilo de vida da sociedade, impactando, dessa forma, fatores importantes que influenciam o comportamento do consumidor. O presente estudo tem como objetivo analisar como as transformações consequentes do novo coronavírus afetaram o comportamento de consumo e, por decorrência, as organizações, em relação às estratégias operacionais do setor supermercadista durante o período de distanciamento social ampliado. A abordagem empregada na pesquisa é de base qualiquantitativa. Os dados analisados foram coletados mediante a aplicação de questionários com seis supermercados de um município no interior de Minas Gerais - dados primários - e por meio da pesquisa em sites especializados em análise de consumo - dados secundários. Os resultados demonstram que houve alterações de demanda em praticamente todas as categorias de produtos vendidos pelo setor supermercadista e que mudanças como frequência de compras, canais de vendas e pagamento com auxílio emergencial fizeram com que os estabelecimentos buscassem estratégias para se adequar às novas necessidades, além de planejar suas demandas e capacidade de abastecimento. Entre as adaptações instituídas, as medidas de higiene e promoção do distanciamento entre pessoas nas lojas físicas se destacam no que respeita aos canais de venda off-line. Para os canais on-line, o setor carece de melhorias em suas estratégias, principalmente nos estabelecimentos do interior, ainda que tenha sido possível perceber que o setor se adaptou à utilização de aplicativos para enfrentar muitos dos desafios atuais.
\end{abstract}

Palavras-chave: Covid-19; setor supermercadista; impactos da pandemia.

\section{THE COVID-19 PANDEMIC AND THE IMPACTS ON THE SUPERMARKET SECTOR: AN ANALYSIS OF THE PANORAMA OF A MUNICIPALITY IN MINAS GERAIS}

\section{ABSTRACT}

The state of hygienic and sanitary emergency that Covid-19 caused in the world generated changes in mobility, income, and lifestyle of the society, thus impacting important factors that influence consumer behavior. The present study aims to analyze how the consequent transformations of the new coronavirus affected the consumption behavior and, consequently, the organizations, regarding the operational strategies of the supermarket sector during the extended social distance period. The approach used in the research is qualitative and quantitative. The analyzed data were collected through the application of questionnaires with six supermarkets in a city in the interior of Minas Gerais - primary data, and researching on websites specialized in consumption analysis - secondary data. The results demonstrate that there were changes in demand in practically all categories of products sold by the supermarket sector, and that changes such as frequency of purchases, sales channels, and payment with the Brazilian emergency assistance made the establishments look for strategies to adapt to the new needs, besides to plan their demands and supply capacities. Among the adaptations implemented, hygiene measures and promoting distance between people in physical stores stand out concerning offline sales channels. The sector still needs to improve its strategies to online channels, mainly in rural establishments, however it was already possible to notice that the sector has adapted to the use of mobile applications to face many of the current challenges.

Keywords: Covid-19; supermarket sector; pandemic impacts.

\footnotetext{
${ }^{1}$ Autora correspondente. Universidade Federal de Ouro Preto (PPGEP) - Campus Morro do Cruzeiro, s/n. Ouro Preto/MG, Brasil. CEP 35400-000. http://lattes.cnpq.br/4762498884701839. https://orcid.org/0000-0002-6668-2871. baccarinigabriella@gmail.com

2 Universidade Federal de Ouro Preto (Ufop). Ouro Preto/MG, Brasil.
} 


\section{INTRODUÇÃO}

No dia 11 de março de 2020 a Organização Mundial da Saúde (OMS) fez uma declaração enquadrando a contaminação da Covid-19, causada pelo novo coronavírus Sars - COV 2, como pandemia (WHO, 2020). Diante disso, legislações e medidas provisórias surgiram, tais como ações de prevenção e mitigação de contágio do vírus, e implicaram mudanças sociais, culturais e econômicas em todo o mundo.

No Brasil, a Lei no 13.979 de 6 de fevereiro de 2020, estabeleceu medidas de enfrentamento do vírus relacionadas à saúde pública, como o isolamento e a quarentena, além de dispor sobre contratações e importações de produtos e serviços necessários ao combate do vírus e possíveis medidas de contenção da mobilidade entre cidades e Estados (BRASIL, 2020a). No que diz respeito à regulamentação trabalhista, a Medida Provisória no 927 estabelece alternativas que poderiam ser adotadas para manutenção dos empregos, como a antecipação de férias, banco de horas e a modalidade de teletrabalho (BRASIL, 2020b).

Nesse contexto, começam a surgir questionamentos sobre as novas configurações de trabalho e normas de segurança higiênico-sanitárias e suas implicações dentro dos setores produtivos de bens e serviços. Mudanças no comportamento do consumidor ocasionam incertezas nos modelos tradicionais de negócios (HASSAN et al., 2020), acarretando intervenções e adaptações rápidas de diversos setores e organizações para criar alternativas que atendam às novas exigências sanitárias, tecnológicas e de consumo.

Tendo isso em vista, o presente estudo busca compreender os impactos no setor de serviços a partir da pandemia da Covid-19, especificamente no setor supermercadista, visando aos desdobramentos no cotidiano de clientes, funcionários e proprietários de lojas de supermercado, especialmente por se tratar de um tipo de negócio classificado como de primeira necessidade e sem condições de paralisar suas atividades durante a pandemia.

Isto posto, este trabalho busca responder às seguintes questões de pesquisa: Como a pandemia da Covid-19 impactou o comportamento do consumidor no setor supermercadista? Quais são as principais modificações e adaptações de estratégias organizacionais ocasionadas pela pandemia da Covid-19 nos supermercados? O objetivo principal desta pesquisa é analisar as transformações ocorridas nos canais de venda e nas estratégias operacionais do setor supermercadista, a partir das mudanças ocorridas no comportamento dos consumidores e das medidas provisórias adotadas durante o período de distanciamento social. Para o alcance do objetivo será explorado o contexto do consumo e dos supermercados em âmbito nacional e será realizada a análise em nível regional dessas transformações em supermercados de um município de Minas Gerais (MG).

Para melhor entendimento do estudo, este está organizado, além desta introdução, da seguinte forma: na segunda seção discutem-se questões relacionadas ao perfil do consumidor e às novas necessidades no contexto pandêmico; na terceira apresentam-se os métodos e procedimentos empregados no desenvolvimento do presente estudo, tais como o tipo de pesquisa e de coleta de dados utilizados para alcançar os objetivos pretendidos; na quarta seção expõe-se a análise de dados e, por fim, no quinto tópico, são apresentadas as principais considerações finais a respeito da investigação. 


\section{O COMPORTAMENTO DO CONSUMIDOR E AS ESTRATÉGIAS ORGANIZACIONAIS}

Ao se analisar o comportamento de um indivíduo em relação às suas compras, deve-se ter em mente que diversos fatores podem e vão influenciar suas decisões. Os valores familiares e/ou religiosos, bem como a nacionalidade e região geográfica de uma pessoa, são exemplos de fatores culturais que podem intervir em seus hábitos de compra (CORRÊA; GIANESI, 2019). Além disso, os grupos de referência do indivíduo, parte dos fatores sociais, e os fatores pessoais tais como idade, condição econômica, estilo de vida, entre outros elementos psicográficos, também interferem diretamente na decisão de compra do usuário (Idem). Esses fatores, somados à motivação, percepção, experiência, convicção e atitude dos usuários, isto é, elementos psicológicos pessoais, são classificados como fatores básicos que influenciam o comportamento de compra (idem).

Segundo Las Casas e Las Casas (2019), existem ainda influências externas ambientais que podem afetar os hábitos de consumo, tais como economia - recessão, inflação, etc. - e política - políticas reguladoras monetárias, fiscais, entre outras. No Brasil, o aquecimento econômico nacional a partir dos anos 2000 trouxe melhorias nas condições econômicas do consumidor. Essas condições somadas à introdução de novas tecnologias, principalmente de comunicação, e o surgimento de varejistas internacionais, fizeram com que o perfil de consumo brasileiro sofresse mudanças, gerando aumento na quantidade de compras realizadas e, como consequência, proporcionando mais exigência na qualidade dos produtos (LAZZARINI et al., 2015).

Com a pandemia da Covid-19, o comportamento do consumidor tende a sofrer novas alterações, gerando maior propensão do crescimento na busca por produtos que proporcionem o sentimento de segurança, tais como produtos de higiene, limpeza e alimentação (REZENDE; MARCELINO; MIYAJI 2020). Nesse sentido, a demanda do setor supermercadista é intensificada (GODDARD, 2020) e, além de fazer parte dos serviços classificados como essenciais à sociedade, o setor encarrega-se do abastecimento domiciliar e do estabelecimento de medidas para atenuar a propagação do vírus.

Com a intenção de atender melhor ao consumidor e de oferecer diferentes experiências de consumo, muitas empresas, de diversos setores, vêm adotando diferentes canais de venda, físicos e on-line/virtuais, adequando suas estratégias de sortimento de produtos, preços e tipos de serviços (MACHADO; CRISPIM, 2017). As lojas on-line possuem vantagens no quesito temporal, pois funcionam 24 horas, além de trazer comodidade quanto à mobilidade (não é necessário o deslocamento até a loja) e, muitas vezes, à competividade de preços (ALMEIDA, 2014). Outro fator positivo a se considerar nos canais on-line é o sortimento dos produtos, podendo ser maior pela capacidade e/ou redução de custos de armazenamento e ainda pela possibilidade de trabalhar com operações de marketplace (MACHADO; CRISPIM, 2017). Nesse sentido, as medidas de distanciamento social provocadas pela pandemia fizeram com que a busca por supermercados que utilizam canais on-line aumentasse e o setor supermercadista tivesse de adaptar seus modelos de negócio e canais de venda para as necessidades dos seus clientes em uma velocidade alta (GODDARD, 2020; HOBBS, 2020).

Berry et al. (2020) destacam que, em contexto pandêmico, medidas que promovam a segurança devem ser instituídas nas organizações para atender às novas necessidades dos clientes. As adaptações e o cumprimento de normas de segurança higiênico-sanitárias pelas empresas podem impactar, ainda, na satisfação e na percepção de competência e de maturidade das orga- 
nizações pelos clientes (SÖDERLUND, 2020 ). Nesse sentido, as organizações devem adaptar suas estratégias, sejam elas de canais de vendas, de suprimentos, de atendimento à demanda, de organização de trabalho ou de modificações na entrega e experiência de serviço, entre outros (BERRY et al., 2020; HALL et al. 2020; KABADAYI; O'CONNOR; TUZOVIC, 2020; SÖDERLUND, 2020).

\section{Comportamento de consumo na pandemia}

Como uma alternativa para avaliar o comportamento do consumidor durante a pandemia, a Nielsen, empresa de informações e coleta de dados, dividiu o padrão de consumo em seis etapas, relacionando-as à propagação do vírus na sociedade - Figura 1. Segundo a Nielsen (2020a), para a criação dessas etapas foi realizada uma análise do comportamento de compra em relação a crises anteriores já vivenciadas pela sociedade, inclusive em casos de pandemia.

Figura 1 - Etapas sobre o comportamento do consumo perante a Covid-19

\section{COVID-19:SEIS ETAPAS NIELSEN SOBRE OS IMPACTOS NO COMPORTAMENTODO CONSUMIDOR}
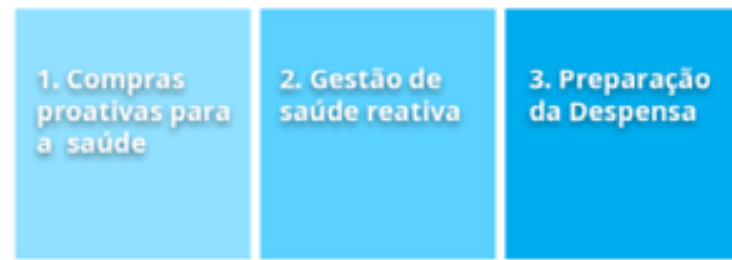
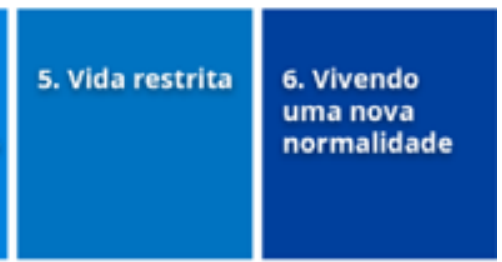

Fonte: NIELSEN (2020a).

A primeira etapa do padrão de consumo definido pela Nielsen representa "Compras proativas para a saúde", um comportamento que também ocorre durante as primeiras notificações de casos do Covid-19. No Brasil, o primeiro caso foi notificado no dia 26 de fevereiro de 2020 (BRASIL, 2020c). Durante essa fase, o consumo de produtos voltados ao abastecimento de emergência remete à incerteza das consequências do vírus no país. A tendência é, portanto, de expansão do consumo de produtos que despertam o sentimento de segurança nos consumidores (BERRY et al., 2020), o que leva ao crescimento do interesse por produtos para manutenção da saúde e do bem-estar durante essa etapa (NIELSEN, 2020a).

A segunda etapa identificada pela Nielsen (Idem), a "Gestão de saúde reativa", é impulsionada durante as primeiras transmissões comunitárias, além das primeiras mortes relacionadas ao vírus causador da pandemia. No dia 13 de março de 2020 é registrado, no Brasil, os primeiros casos de coronavírus por transmissão comunitária, e a primeira morte por Covid-19 ocorreu no dia 16 de março (BRASIL, 2020c). Nesse cenário, o comportamento de consumo mostra a preferência por produtos que oferecem proteção ao consumidor para o enfrentamento do vírus. Segundo a Nielsen (2020a), a prioridade de compras nessa etapa é por produtos de saúde e segurança pública, que são essenciais para a contenção do vírus.

A terceira etapa do comportamento do consumidor, segundo a Nielsen (Idem), é chamada de "Preparação da despensa" e ocorre quando o vírus começa a se espalhar e novas notificações de contágio começam a surgir. No Brasil, o Ministério da Saúde declarou transmissão 
comunitária no dia 20 de março de 2020 e aconselhou os gestores nacionais a empregarem medidas antiaglomeração e de distanciamento social (BRASIL, 2020d). O medo e a incerteza dos consumidores, à medida que o vírus começa a se espalhar, impulsiona o comportamento de estoque (GODDARD, 2020; HALL et al., 2020). Sendo assim, durante essa etapa, os consumidores começam a armazenar alimentos e produtos que remetem ao sentimento de segurança alimentar e de saúde.

Na quarta etapa, o número de casos de Covid-19 continua aumentando, e, ainda segundo a pesquisa da Nielsen, a fase de "Preparação para quarentena" se dá por meio da redução das idas às lojas físicas e do aumento de compras on-line. Esse comportamento é coerente com as medidas governamentais de restrição à livre circulação dos brasileiros (BRASIL, 2020d) e com as mudanças provocadas na sociedade, tais como modificações no estilo de vida, isto é, nos fatores pessoais (CORRÊA; GIANESI, 2019) e nas características de motivação de compras, parte dos fatores psicológicos (Idem) que impactam no comportamento de consumo. Ademais, as compras on-line possuem vantagem no quesito de deslocamento (ALMEIDA, 2014), já mencionado anteriormente, o que vai colaborar sobremaneira para o comportamento de crescimento do consumo on-line.

A quinta etapa do comportamento do consumidor identificada pela Nielsen (2020a) refere-se ao período em que os casos da Covid-19 apresentam crescimento acentuado e as restrições de mobilidade tornam-se maiores. Segundo a classificação, durante essa etapa, denominada "Vida restrita", os consumidores começam a expressar preocupação com o aumento dos preços dos produtos e as viagens de compras são restritas. No Brasil, apesar do fechamento temporário de atividades não essenciais - como comércio, áreas de lazer, instituições religiosas, entre outros - não houve, até o fechamento deste trabalho, um período de restrição massiva. Além disso, no final do mês de maio e início do mês de junho de 2020, algumas capitais do país, como São Paulo, Rio de Janeiro, Belo Horizonte, Fortaleza e Manaus, iniciam protocolos de reabertura e flexibilização do comércio e de atividades econômicas em geral, apesar do crescente número de casos. No dia 19 de maio de 2020 o Brasil registra mais de 1.000 mortes pelo coronavírus em 24 horas, e no dia 22 de maio torna-se o segundo país no mundo com maior número de infectados (BRASIL, 2020c).

A sexta e última etapa classificada pela Nielsen (2020a), "Vivendo uma nova realidade", diz respeito à vida após controle da Covid-19 e à normalização das atividades e rotinas diárias dos consumidores. O Brasil ainda não chegou nessa fase, no entanto a propensão nessa etapa é que o consumidor continue realizando suas compras com cautela e cuidado com sua segurança e saúde. Os consumidores serão mais exigentes com os protocolos de segurança e de higiene, sendo assim, as organizações terão de considerar estratégias que possam promover o bem-estar de seus clientes diante do novo cenário (KABADAYI; O'CONNOR; TUZOVIC, 2020).

\section{MÉTODO E PROCEDIMENTOS}

A presente pesquisa é classificada como aplicada, devido ao interesse de analisar e trazer contribuições práticas para as organizações (TURRIONI; MELLO, 2012) sobre as mudanças provocadas no contexto da pandemia. A abordagem empregada é de base mista, quali-quantitativa, dado que a combinação das abordagens permite que explicações e inferências sejam realizadas sobre comportamentos encontrados nos dados quantitativos (MARTINS, 2012). Por 
um lado, a perspectiva qualitativa busca compreender as especificidades e os comportamentos do fenômeno estudado a partir das interpretações e observações críticas dos dados (FERREIRA, 2015). Por outro lado, a partir de estratégias quantitativas, será possível mensurar e analisar os dados de forma objetiva com o intuito de verificar a causalidade entre as variáveis (MARTINS, 2012). Para análise quantitativa será realizada a análise estatística descritiva dos dados extraídos dos bancos de dados primários e secundários selecionados para esse estudo.

Nesse sentido, os objetivos da pesquisa são de caráter exploratório, em que se pretende levantar informações para auxiliar na compreensão do problema proposto (TURRIONI; MELLO, 2012). Em uma pesquisa de abordagem mista, o caráter exploratório deve ser utilizado para que o tema possa ser explorado e propicie subsídios para os dados mensuráveis (MARTINS, 2012), além de fornecer maior familiaridade com o problema proposto (TURRIONI; MELLO, 2012).

\section{Coleta de dados}

A coleta dos dados aqui analisados ocorreu em dois momentos distintos: o primeiro foi realizado a partir do levantamento de dados secundários em sites e relatórios de empresas de informação e de pesquisa e o segundo, mediante aplicação de questionário com supermercados locais de um município do interior de Minas Gerais. Dessa forma, foi possível relacionar os dados de estabelecimentos locais (dados primários) com os dados que compõem o cenário nacional de consumo (dados secundários), permitindo, assim, aumentar a representatividade do estudo e, ainda, cruzar dados e analisar de forma mais profunda as informações levantadas (TURRIONI; MELLO, 2012).

Os dados secundários foram levantados e analisados a partir da perspectiva do contexto de pandemia e suas implicações dentro do período de distanciamento social ampliado em que se encontrava o país durante o desenvolvimento deste estudo. Para a coleta desses dados foram utilizados sites e relatórios de pesquisas de empresas de informações e pesquisa de consumo, sendo elas: GS Ciência do Consumo (GIBOTTI et al., 2020a, 2020b, 2020c, 2020d, 2020e, 2020f), Nielsen Company (NIELSEN, 2020b, 2020c, 2020d) e Kantar Brasil Insights (GAMBARO, 2020; KANTAR, 2020a, 2020c).

A partir das evidências coletadas, implicações iniciais foram estabelecidas para o desenvolvimento da coleta de dados primários da pesquisa, isto é, com os estabelecimentos supermercadistas. $O$ método de coleta de dados primários empregado foi a aplicação de questionários semiabertos, em que a ausência do pesquisador durante o preenchimento das perguntas reduz o risco de distorção das respostas e dá uma liberdade maior ao respondente (TURRIONI; MELLO, 2012).

O questionário foi desenvolvido a partir das implicações encontradas no referencial teórico sobre mudanças provocadas no comportamento do consumidor diante da pandemia. Ademais, as análises preliminares dos dados secundários auxiliaram a criar e a direcionar perguntas específicas para o setor supermercadista. 0 documento, contendo 20 questões, foi aplicado de forma virtual, e o link para acesso e preenchimento foi enviado por e-mail aos estabelecimentos participantes do estudo.

Os supermercados analisados pertencem a um município do interior do Estado de Minas Gerais, localizado na região do Campo das Vertentes. Inicialmente, todos os supermercados locais do município, um total de dez estabelecimentos, foram convidados para participar da pesquisa. 
Foram considerados apenas os estabelecimentos locais que não atendem estratégias específicas de grandes redes e que atuam na modalidade de varejo e no formato de loja/ supemercado. Seis supermercados responderam positivamente ao convite e participaram da pesquisa.

Os supermercados se diferenciam das demais lojas pela estratégia adotada de sortimento, com uma alta variedade de produtos, diferenciando-se de empórios e de mercearias, e contam, ainda, com dimensões e quantidades bem maiores se comparados a minimercados (SEBRAE, 2016). Já os hipermercados caracterizam-se pela adição de itens de magazine, como venda de roupas e acessórios (idem) e também não foram considerados no estudo.

As 20 questões presentes no questionário aplicado foram desenvolvidas considerando cinco blocos de levantamento de dados - Quadro 1 . O primeiro bloco é formado pelo perfil do respondente, em que são realizadas perguntas sobre o nome do estabelecimento e o cargo do respondente. $\mathrm{O}$ segundo bloco pretende medir as mudanças no comportamento dos clientes dos estabelecimentos (REZENDE; MARCELINO; MIYAJI, 2020; GODDARD, 2020), com cinco perguntas direcionadas para a mudanças de demanda/venda, frequência de visitas ao estabelecimento e método de pagamento. $O$ terceiro bloco é direcionado para as estratégias de venda (GODDARD, 2020; HALL et al., 2020), em que constam cinco perguntas sobre mudanças e adaptações nos canais de vendas e de ofertas, além de alterações nas funções internas para atender a essas novas estratégias. O quarto bloco, composto de cinco perguntas, é voltado para o levantamento das adaptações no ambiente físico que promovam a segurança e o distanciamento (BERRY et al., 2020; SÖDERLUND, 2020), com o intuito de reduzir a probabilidade de propagação do vírus. $O$ último bloco é composto por três perguntas que pretendem identificar dificuldades encontradas com mão de obra e desabastecimento de produtos (KABADAYI; O'CONNOR; TUZOVIC, 2020; HOBBS, 2020), além de entender quais estratégias os supermercadistas pretenderm manter no mundo pós-pandemia.

Quadro 1 - Operacionalização dos objetivos pretendidos

\begin{tabular}{|c|l|c|l|}
\hline Bloco & \multicolumn{1}{|c|}{ Objetivos Pretendidos } & No de perguntas & \multicolumn{1}{|c|}{ Embasamento teórico } \\
\hline 1 & Perfil da empresa e respondente & 2 & \multicolumn{1}{c|}{ - } \\
\hline 2 & Mudanças no comportamento de clientes & 5 & $\begin{array}{l}\text { Rezende, Marcelino e Miyaji, } \\
\text { (2020); Goddard (2020) }\end{array}$ \\
\hline 3 & Estratégias de venda & 5 & $\begin{array}{l}\text { Goddard (2020); Hall et al. } \\
\text { (2020) }\end{array}$ \\
\hline 4 & $\begin{array}{l}\text { Adaptações no ambiente promovendo } \\
\text { segurança e distanciamento }\end{array}$ & 5 & $\begin{array}{l}\text { Berry et al. (2020); Söderlund } \\
\text { (2020) }\end{array}$ \\
\hline 5 & $\begin{array}{l}\text { Dificuldades encontradas e estratégias que } \\
\text { continuarão a ser adotadas }\end{array}$ & 3 & $\begin{array}{l}\text { Kabadayi, O'Connor e } \\
\text { Tuzovic, (2020); Hobbs (2020) }\end{array}$ \\
\hline
\end{tabular}

Fonte: Autores.

\section{Análise de dados}

Tanto os dados secundários quanto as informações coletadas por meio dos questionários foram analisados pelos pesquisadores de forma a refletir sobre as mudanças no comportamento do consumidor e as adaptações realizadas pelo setor supermercadista diante da pandemia de Covid-19. Os dados primários e secundários foram analisados conjuntamente, de forma suplementar, considerando as especifidades locais dos estabelecimentos diante do panorama na- 
cional. Ademais, em alguns casos, a análise também foi realizada de forma comparativa, com o intuito de, ao cruzar informações, alcançar os objetivos da pesquisa.

Para apresentação dos dados foram utilizadas as etapas do comportamento do consumidor no contexto pandêmico elaboradas pela empresa especializada em informações de consumo e mídia, Nielsen (2020a), já apresentadas no referencial teórico. Essas etapas foram criadas pela Nielsen a partir de um estudo sobre as pandemias anteriores e dos comportamentos preliminares já vivenciados por outros países, e têm o intuito de auxiliar o mercado para o preparo no abastecimento das prateleiras e adaptações de estratégias para o contexto atual.

\section{ANÁLISE E RESULTADO DOS DADOS}

A seguir são apresentadas e analisadas as principais informações encontradas em relação ao setor supermercadista em âmbito nacional, além dos dados coletados pelos questionários aplicados nos supermercados estudados, especialmente no momento de avanço da pandemia. Como forma de organizar a discussão, esta seção está dividida em duas subseções, sendo discutido o comportamento de consumo na primeira e as adaptações do setor supermercadista na segunda.

\section{Comportamento de consumo}

As etapas do comportamento de consumo durante a pandemia, elaboradas pela Nielsen (2020a), apresentadas no referencial teórico deste trabalho, servirão como suporte para a apresentação, nesta seção, dos hábitos de compra e de consumo levantados por meio desta pesquisa.

Ao se analisar o comportamento do consumo brasileiro durante a primeira etapa - "Compra proativa de saúde" - a partir de informações encontradas nos bancos de dados da Nielsen (op. cit.), a busca elevada de produtos teve foco em itens de prevenção da doença, tais como: álcool em gel (+623\%), filtros de ar $(+100 \%)$, álcool (+85\%), produtos de limpeza em geral (+58\%) e sabão líquido (+33\%).

Nos supermercados estudados, apenas um estabelecimento relatou aumento na busca de itens da categoria de limpeza no final do mês de fevereiro de 2020, no entanto foi a única categoria que sofreu alteração no consumo durante esse mês. Ademais, quatro dos seis supermercados participantes da pesquisa sinalizaram aumento desses itens no mês de março/2020. É importante ressaltar que todos os estabelecimentos relataram aumento de busca por essa categoria, ainda que em períodos um pouco diferentes, e a maioria dos estabelecimentos informou ter tido problemas de abastecimento de álcool em gel e/ou líquido nas prateleiras dos supermercados no início da pandemia.

Considerando os dados da Nielsen (2020a), durante a segunda etapa de consumo - "Gestão de saúde reativa" - os produtos que tiveram alta de venda em âmbito nacional foram os essenciais à saúde e à manutenção de itens básicos, tais como os alimentos commodities: arroz, feijão, café, açúcar e farinha (+31\%), limpeza (+21\%), higiene e beleza $(+25 \%)$, mercearia $(+18 \%)$, medicamentos $(+13 \%)$ e perecíveis $(+11 \%)$.

Tanto na categoria de alimentos da cesta básica quanto na categoria de higiene pessoal, $50 \%$ dos supermercados analisados relataram aumento, no mês de março/2020, e 50\% a partir do mês de abril/2020, isto é, os efeitos do aumento de demanda de itens também ocorreu nos 
estabelecimentos locais, seguindo a tendência nacional, apesar de um pouco tardios em alguns supermercados. Esse fato pode estar relacionado com o aparecimento também tardio - a partir de 26 de março de 2020 - de casos positivos de Covid-19 no município estudado. 0 aumento de consumo dessas categorias vai ao encontro ao proposto por Rezende, Marcelino e Miyaji, (2020), em que o consumidor, em períodos de emergência como o ocasionado pela pandemia, aumenta sua busca por produtos que ocasionem segurança à sua saúde e bem-estar.

Durante o período compreendido na terceira etapa do comportamento de consumo, "Preparação da despensa", segundo dados retirados de relatórios da GS Ciência e Consumo, os supermercados e atacados brasileiros tiveram uma alta de $73,4 \%$ no faturamento devido à preparação para a confinação e aos rumores sobre problemas no abastecimento dos supermercados, resultando na procura elevada de produtos para estocagem, o que gerou um aumento de $40 \%$ na quantidade de itens presentes no carrinho de compras da população. Em consonância com esses dados, todos os estabelecimentos participantes desta pesquisa notaram mudanças na frequência de visitas por seus clientes, destacando-se que cinco dos seis supermercados relataram, ainda, que a quantidade de itens/produtos nos carrinhos dos seus clientes estava maior durante as visitas às lojas.

A partir desses dados é possível inferir que as medidas como o distanciamento social e o fechamento temporário de algumas atividades econômicas, além das alterações nas modalidades de trabalho e no estilo de vida da sociedade, causaram impactos nos fatores sociais, pessoais e psicológicos dos consumidores. Sendo assim, afetaram a forma de consumo nos setores supermercadistas, em que se constatou, pelos dados apresentados, alterações de demanda de produtos vendidos dentro dos supermercados, além de mudanças na frequência de compra por parte dos clientes.

Corroborando o comportamento previsto para a quarta etapa do padrão de consumo da Nielsen (2020a), "Preparação para a quarentena", informações contidas no relatório da Kantar demonstram que houve redução da frequência de visitas aos pontos de venda no Brasil e, em contrapartida, um aumento na quantidade de itens por viagem. Além disso, segundo dados dos relatórios da GS Ciência do Consumo, durante a primeira quinzena de abril de 2020, a frequência de clientes nos supermercados e atacados teve queda de 5,57\%, porém o ticket médio teve aumento de $14,01 \%$ e o faturamento durante esse período teve um aumento de $28 \%$. Na segunda quinzena de abril/2020 a frequência de clientes nesses estabelecimentos continuou caindo e reduziu em $8,59 \%$, mas com aumento de $12,9 \%$ do ticket médio e de $25,01 \%$ no faturamento.

No que diz respeito ao aumento de vendas on-line, em outro relatório da Kantar é estimado que o e-commerce cresceu cerca de 2,3 vezes no país durante as quatro primeiras semanas após o estabelecimento de fechamento do comércio. Em relação ao setor supermercadista, dados encontrados na pesquisa da Konduto e ABComm (2020) revelam que também houve tendência positiva de crescimento de compras realizadas pelo e-commerce, chegando a um aumento de $270,17 \%$ de variação de pedidos por dia entre as semanas de 15 a 28 de março de 2020, continuando a crescer nas quatro semanas seguintes, porém em um ritmo menos acelerado.

Além disso, segundo dados da Nielsen, entre os dias 18 e 24 de março/2020, do número total de consumidores que fizeram suas compras no e-commerce brasileiro, mais de $32 \%$ eram aqueles que realizaram sua primeira compra on-line de produtos relacionados ao autosserviço (alimentos, bebidas, produtos de higiene, etc.), normalmente referente a supermercados. No 
dia 22 de março daquele ano, após o estabelecimento de medidas de distanciamento social ampliado, a porcentagem referente à primeira compra no e-commerce foi de $45 \%$ dos consumidores.

Dentro dos supermercados que participaram da pesquisa, apenas um dos seis possui site para vendas, no entanto, quando perguntados sobre as estratégias adotadas para se adequar à busca por compras on-line, todos os estabelecimentos disseram usar o aplicativo WhatsApp para receber lista de compras de seus clientes. Além dessa ferramenta, 83,3\% utilizam o telefone do estabelecimento para receber pedidos de compras, e $66,67 \%$ usam também redes sociais como Facebook e Instagram para o mesmo fim. Dessa forma, apesar de os estabelecimentos locais do interior de Minas Gerais não possuírem sites e canais de venda on-line mais consolidados, as adaptações a novos canais de venda para adequar às necessidades dos clientes em momento de pandemia foram intensificadas e/ou estabelecidas.

Apesar de, até o momento, ainda não ter havido um período de restrição acentuada no país, que corresponderia à quinta etapa do comportamento de consumo, a mobilidade reduzida e a emergência de saúde pública fizeram com que os consumidores brasileiros se preocupassem com a crise econômica que a pandemia gera (REZENDE; MARCELINO; MIYAJI, 2020). Em um levantamento realizado pela Nielsen, com 13 países da América Latina, 53\% dos consumidores trabalham em setores informais e estão cada vez mais preocupados com suas compras relacionadas à saúde e à alimentação.

Especificamente no Brasil, dados obtidos por meio do relatório da Kantar mostram que $34 \%$ dos consumidores afirmaram que a pandemia afetou muito seu planejamento financeiro, enquanto $43 \%$ revelaram que houve algum impacto, e apenas $11 \%$ alegaram não ter afetado em nada suas finanças. No que diz respeito à renda familiar, no final de março de 2020, $43 \%$ dos brasileiros afirmaram que a pandemia já havia impactado na sua renda. Em meados de abril daquele mesmo ano esse número passa para $51 \%$ e no final desse mês para $55 \%$. Em comparação com outros países, esse impacto na renda familiar brasileira foi acima da média - globalmente, esses números foram $38 \%, 44 \%$ e $45 \%$ respectivamente.

Outro aspecto relevante sobre o consumidor brasileiro e a crise econômica anunciada pela pandemia é que, segundo informações da Editora Brasileira do Comércio, por meio do seu portal "Newtrade" (NEWTRADE, 2020b), 15\% dos brasileiros contraíram dívidas após o início do distanciamento social no país. A pesquisa revela ainda que apenas $36 \%$ dos brasileiros disseram estar recebendo o salário normalmente, enquanto $23 \%$ disseram ter ficado sem renda e $17 \%$ tiveram redução parcial de sua renda mensal.

Como medida para atenuar os impactos econômicos causados pela pandemia, após pressão de governadores e da Câmara dos Deputados, foi instituído pelo governo federal o auxílio emergencial pela lei no 13.982 de 2 de abril de 2020, que concedeu o valor de $\mathrm{R} \$ 600,00$ (podendo gerar até duas cotas em casos de mulher provedora de família monoparentais) para trabalhadores informais, microempreendedores e contribuintes individuais (BRASIL, 2020e). A GS Ciência do Consumo fez uma pesquisa com consumidores e constatou que $28 \%$ dos entrevistados solicitaram o benefício e, destes, $55 \%$ disseram que utilizariam o dinheiro para quitar contas gerais e $31 \%$ para realizar compras no supermercado.

Nos estabelecimentos supermercadistas locais analisados, ao serem perguntados sobre o uso desse auxílio para efetuar compras nos estabelecimentos analisados, todos os responden- 
tes afirmaram aceitar o auxílio como forma de pagamento. Além disso, cinco dos seis supermercados relataram que há bastante procura pelo pagamento com o auxílio emergencial por parte dos seus clientes e apenas um estabelecimento constatou que a adesão ainda é baixa.

No que diz respeito à última etapa do comportamento de consumo identificada pela Nielsen (2020a), "Vivendo uma nova realidade", o Brasil ainda não chegou nessa fase e, dessa forma, não foi possível coletar dados do comportamento do consumidor para essa etapa.

No Quadro 2 as etapas do comportamento do consumo perante a pandemia e os dados secundários (âmbito nacional) e primários (local) levantados são apresentados de forma resumida.

Quadro 2 - Mudanças encontradas no comportamento de consumo perante a Covid-19

\begin{tabular}{|c|c|c|c|}
\cline { 2 - 5 } \multicolumn{1}{c|}{} & $\begin{array}{c}\text { Etapas Nielsen } \\
\text { (2020a) }\end{array}$ & $\begin{array}{c}\text { Mudanças no comportamento } \\
\text { nacional }\end{array}$ & $\begin{array}{c}\text { Mudanças no comportamento de } \\
\text { estabelecimentos locais }\end{array}$ \\
\hline $\begin{array}{c}\text { Primeira } \\
\text { etapa }\end{array}$ & $\begin{array}{c}\text { Compra proativa } \\
\text { de saúde }\end{array}$ & $\begin{array}{c}\text { Aumento da busca de produtos de } \\
\text { prevenção do vírus (álcool em gel, } \\
\text { filtro de ar, produtos de limpeza e } \\
\text { sabão líquido) }\end{array}$ & $\begin{array}{c}\text { Aumento da busca de produtos } \\
\text { de limpeza e álcool em gel }\end{array}$ \\
\hline $\begin{array}{c}\text { Segunda } \\
\text { etapa }\end{array}$ & $\begin{array}{c}\text { Gestão reativa da } \\
\text { saúde }\end{array}$ & $\begin{array}{c}\text { Aumento da busca de produtos de } \\
\text { alimentação da cesta básica, limpeza, } \\
\text { higiene e beleza, medicamentos e } \\
\text { perecíveis }\end{array}$ & $\begin{array}{c}\text { Aumento da busca de produtos } \\
\text { da cesta básica e de higiene } \\
\text { pessoal }\end{array}$ \\
\hline $\begin{array}{c}\text { Terceira } \\
\text { etapa }\end{array}$ & $\begin{array}{c}\text { Preparação da } \\
\text { despensa }\end{array}$ & $\begin{array}{c}\text { Aumento geral na demanda e na } \\
\text { quantidade de itens por carrinho }\end{array}$ & $\begin{array}{c}\text { Alterações na frequência } \\
\text { de compras e aumento na } \\
\text { quantidade de itens por carrinho }\end{array}$ \\
\hline $\begin{array}{c}\text { etapa } \\
\text { quarta }\end{array}$ & $\begin{array}{c}\text { Preparação para } \\
\text { quarentena }\end{array}$ & $\begin{array}{c}\text { Redução na frequência de compras, } \\
\text { aumento na quantidade de itens por } \\
\text { carrinho e aumento de compras on- } \\
\text { line, no e-commerce }\end{array}$ & $\begin{array}{c}\text { Aumento de compras por canais } \\
\text { on-line como site, WhatsApp, } \\
\text { Instagram, Facebook, além de } \\
\text { recebimento de lista de compras } \\
\text { por telefone }\end{array}$ \\
\hline $\begin{array}{c}\text { Sexta } \\
\text { Etapa }\end{array}$ & $\begin{array}{c}\text { Viver uma nova } \\
\text { realidade }\end{array}$ & $\begin{array}{c}\text { Impactos e/ou preocupações sobre a } \\
\text { restrições } \\
\text { renda familiar e utilização do auxílio } \\
\text { efetuar compras em supermercados }\end{array}$ & $\begin{array}{c}\text { Utilização elevada do auxílio } \\
\text { emergencial para compras }\end{array}$ \\
\hline
\end{tabular}

Fonte: Autores.

Na próxima seção serão discutidas as principais transformações e adaptações que os estabelecimentos supermercadistas tiveram de colocar em prática nos seus estabelecimentos para atender a essas novas demandas e necessidades do consumidor.

\section{Adaptações do setor supermercadista}

A segurança no processo de compra passa a ser um fator muito preocupante para os consumidores brasileiros em meio à pandemia. De acordo com informações retiradas do relatório da GS Ciência e Consumo, os cuidados com a higienização e limpeza foram apontados como os aspectos mais relevantes de mudanças no dia a dia dos consumidores.

Os gestores do varejo também revelam preocupação com a segurança dos colaboradores e dos clientes nesse contexto e, de acordo com outro relatório da GS Ciência do Consumo, entre as principais medidas tomadas pelos varejistas está a higienização e a limpeza dos espaços, 
além do controle de acesso do cliente em lojas físicas e políticas de distanciamento entre clientes e funcionários nas filas de espera. Na Figura 2 são apresentadas as principais mudanças e medidas empregadas pelos varejistas nacionalmente.

Figura 2 - Mudanças e medidas tomadas na pandemia em âmbito nacional

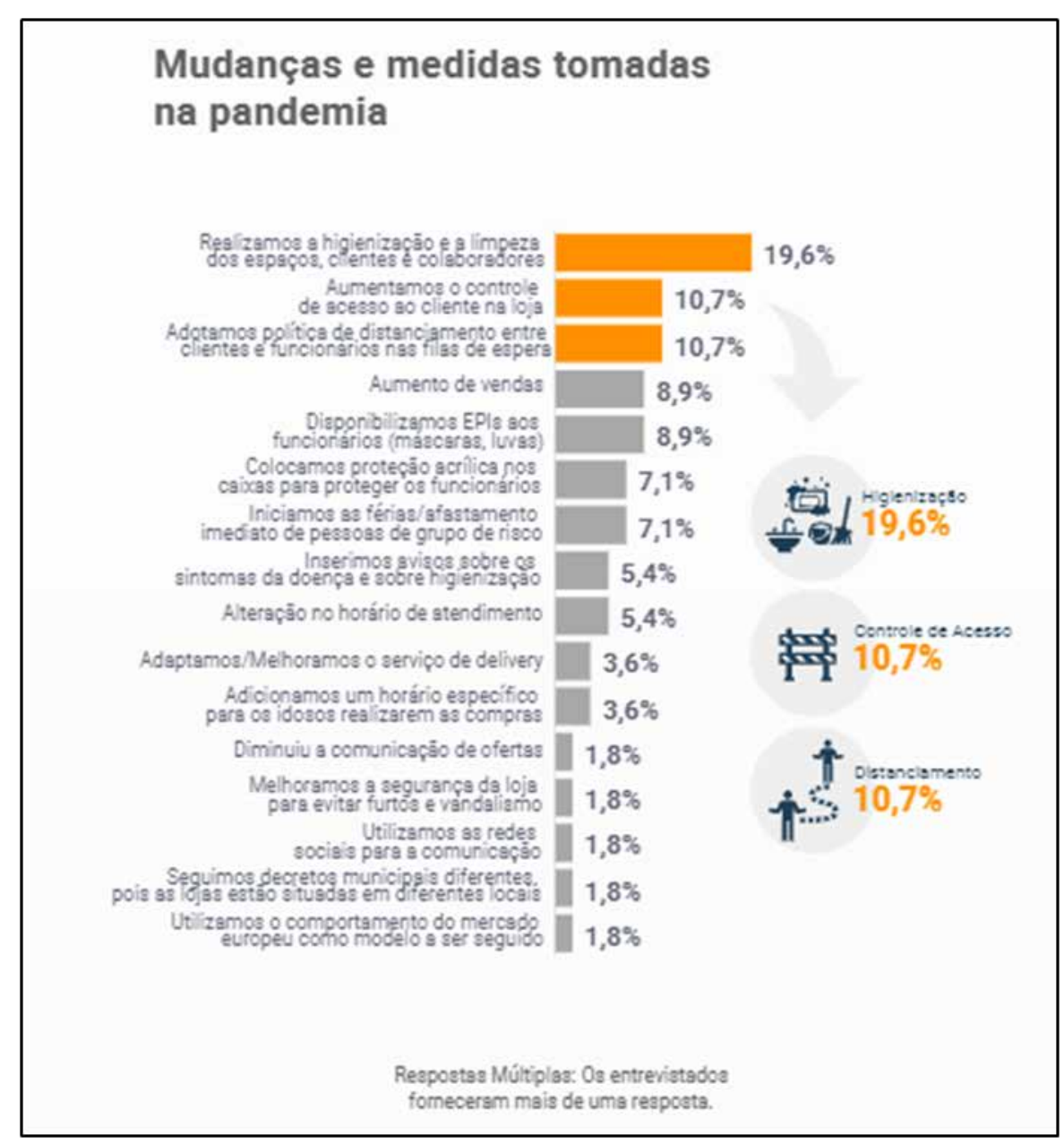

Fonte: GIBOTTI et al. (2020f).

Em concordância com as adaptações nacionais, o uso de máscara e a disponibilização de álcool em gel aparecem como as principais medidas adotadas pelos estabelecimentos supermercadistas do interior de Minas Gerais participantes desta pesquisa. Essas medidas foram aplicadas com o intuito de ajudar na segurança do colaborador, tanto para os funcionários que mantêm contato direto com o cliente - tais como caixas de check out, atendentes de açougue, hortifruti, etc. - quanto para os funcionários que trabalham na retaguarda.

Somadas a essas medidas, outras adaptações internas foram necessárias para ajudar na proteção dos colaboradores dos supermercados analisados. As diretrizes adotadas foram: orientação aos clientes sobre manter distância dos balcões dos colaboradores, afastamento dos caixas de check out para manter o distanciamento e/ou uso de barreiras de proteção nesses caixas, uso de adesivos no chão da loja para impor o distanciamento e a higienização nos locais de maior contato de pessoas. 
Essas adaptações também surgem como medidas de segurança para os clientes dos estabelecimentos estudados. Os supermercados relataram, ainda, que a disponibilização do álcool em gel também é estendida ao cliente, assim como a exigência do uso de máscaras. Além disso, a marcação no chão da loja nos locais que geram filas também aparece como medida adotada, e a higienização e limpeza dos carrinhos e cestas de compra também é realizada regularmente para aumentar a proteção para os compradores.

Outra intervenção empregada pelos supermercados analisados foi a barreira na entrada das lojas físicas. Os estabelecimentos bloquearam boa parte da entrada da loja, limitando a abertura das portas, com o intuito de controlar o fluxo de entrada dos clientes e, ainda, para facilitar o monitoramento e a limitação de número de pessoas dentro do supermercado. Alguns estabelecimentos (três dos seis) separaram horário especial para atendimento de pessoas com mais de 60 anos e/ou pertencentes a grupos de riscos da pandemia.

Uma das adaptações importantes para a estratégia do estabelecimento, realizada pelos supermercados participantes desse estudo, diz respeito aos meios de comunicação de ofertas: $83,3 \%$ dos estabelecimentos, por medida de segurança para os clientes, pararam de usar o foIheto impresso e passaram a utilizar publicações em redes sociais do estabelecimento como principal via de divulgação de ofertas; $50 \%$ desses estabelecimentos utilizam também o impulsionamento pago nessas redes para atingir um maior número de consumidores. A utilização de folhetos eletrônicos e/ou divulgação de ofertas por redes sociais é uma estratégia que pode auxiliar na atração de novos clientes, além de ser uma opção que exige baixo ou nenhum investimento financeiro e que permite atingir um grande número de pessoas.

Além das mudanças nas lojas físicas, os canais de venda on-line passaram a ser uma opção mais presente para as empresas durante a pandemia, no entanto o setor supermercadista ainda investe muito pouco no e-commerce e nas vendas on-line. De acordo com Mariotti (2020), apenas 18 das 50 maiores redes de supermercados do Brasil possuem e-commerce. Diante do cenário pandêmico, algumas grandes empresas varejistas, como a GPA - dona das redes Pão de Açúcar, Extra e Assaí - estão antecipando o recurso de marketplace de forma a adequar suas estratégias às novas demandas do mercado.

Além disso, o aceleramento da digitalização do comércio e a alta procura por alimentos e bebidas fizeram com que empresas grandes e conhecidas que já utilizavam estratégias de marketplace, tais como Mercado Livre, Magazine Luiza e B2W Digital (Americanas, Submarino e Shoptime) apostassem no segmento de supermercados em suas plataformas on-line.

É importante ressaltar que ainda existe uma certa resistência para a compra on-line por parte dos consumidores que possuem pouca habilidade digital. Apesar do alto crescimento de vendas on-line e no e-commerce, as informações coletadas por meio da pesquisa da GS Ciência do Consumo constataram que $70 \%$ dos consumidores com menos de 60 anos e $53,3 \%$ dos consumidores com 60 anos ou mais ainda estavam realizando suas compras presencialmente na segunda quinzena de março de 2020. Seguindo essa lógica de integração digital para os clientes com maior dificuldade, a GS Ciência do Consumo desenvolveu um sistema que possui um ataIho de compra direcionado ao aplicativo WhatsApp dentro dos aplicativos de compras de seus clientes varejistas, incentivando que esses consumidores realizem suas compras de forma on-line com maior tranquilidade e comodidade. 
Conforme discutido anteriormente no tópico Comportamento de consumo, os supermercados analisados neste trabalho utilizam o WhatsApp, o telefone do estabelecimento e as redes sociais para atender pedidos de lista de compra, sendo que, à época da coleta de dados, apenas um supermercado utilizava site para receber pedidos. Os estabelecimentos também relataram que o mix de produtos ofertados em todos os canais são os mesmos. Sobre as entregas das compras realizadas pelos canais on-line/digitais, os produtos referentes à lista de compras enviada pelos clientes para o supermercado podem ser retirados no próprio estabelecimento ou serem entregues no domicílio do cliente.

Para atender às novas estratégias instituídas, alguns estabelecimentos tiveram de direcionar colaboradores para administrar as redes sociais e/ou para realizar o atendimento das listas de compras e pedidos realizados nos canais on-line dos supermercados estudados. Ainda sobre a mão de obra, apesar de a maioria dos estabelecimentos ter declarado não ter tido problemas com falta de funcionários, um estabelecimento relatou ocorrência de faltas relacionadas à Covid-19 pelos funcionários que fazem parte de grupos de risco.

Os estabelecimentos alegam, ainda, que o emprego dos canais digitais, principalmente a utilização para comunicação e para a oferta/vendas de produtos pelo WhatsApp continuará a funcionar após a normalização das atividades no país. Um dos respondentes do questionário relatou que essa ferramenta foi muito importante nesse momento de pandemia e que o estabelecimento pretende utilizar, cada vez mais, o canal.

A simplicidade na interface do aplicativo WhastApp e o fator cultural de utilização - segundo Valente (2019), é a plataforma mais popular no Brasil juntamente com o Facebook -podem ser os motivos pelos quais os consumidores sentem maior disposição e comodidade para realizar suas compras nesse canal, principalmente aqueles que apresentam maior dificuldade de integração digital.

A maioria dos estabelecimentos estudados nesta pesquisa relatou não possuir canal de comunicação e de ofertas de produtos pelo e-commerce e, assim, tiveram de realizar a integração de canais on-line e off-line (lojas físicas) a partir da utilização e adaptação de tecnologias presentes nos aplicativos de mensagens e redes sociais para manter e alavancar o contato com seus clientes.

No que diz respeito às principais adaptações adotadas pelos supermercados locais estudados, quatro categorias emergiram da análise desses dados, ou seja: Itens e proteção e contenção do vírus; Mecanismos de controle contra aglomerações; Limpeza e Higienização; Mudanças nos processos internos - Quadro 3. Essas categorias representam as principais preocupações e transformações que tiveram de ser realizadas pelos estabelecimentos para promover a segurança dos colaboradores e clientes, além de atender aos novos comportamentos de consumo provocados pela pandemia.

É importante destacar que as tendências digitais, aceleradas pela pandemia, permitiram que os supermercados instituíssem estratégias multicanais em seus processos e, consequentemente, atendessem às recomendações de distanciamento social e se adequassem aos novos hábitos dos seus clientes, além de permitir o estreitamento de relacionamento com o usuário multicanal. Com essas adaptações, a integração entre os canais on-line e off-line passa a ser um importante item de gestão para os estabelecimentos. 
A PANDEMIA DE COVID-19 E OS IMPACTOS NO SETOR SUPERMERCADISTA: UMA ANÁLISE DO PANORAMA DE UM MUNICÍPIO DE MINAS GERAIS

Gabriella Baccarini de Carvalho - Wellington Tavares

Quadro 3 - Principais adaptações realizadas por supermercados de um município do interior de MG

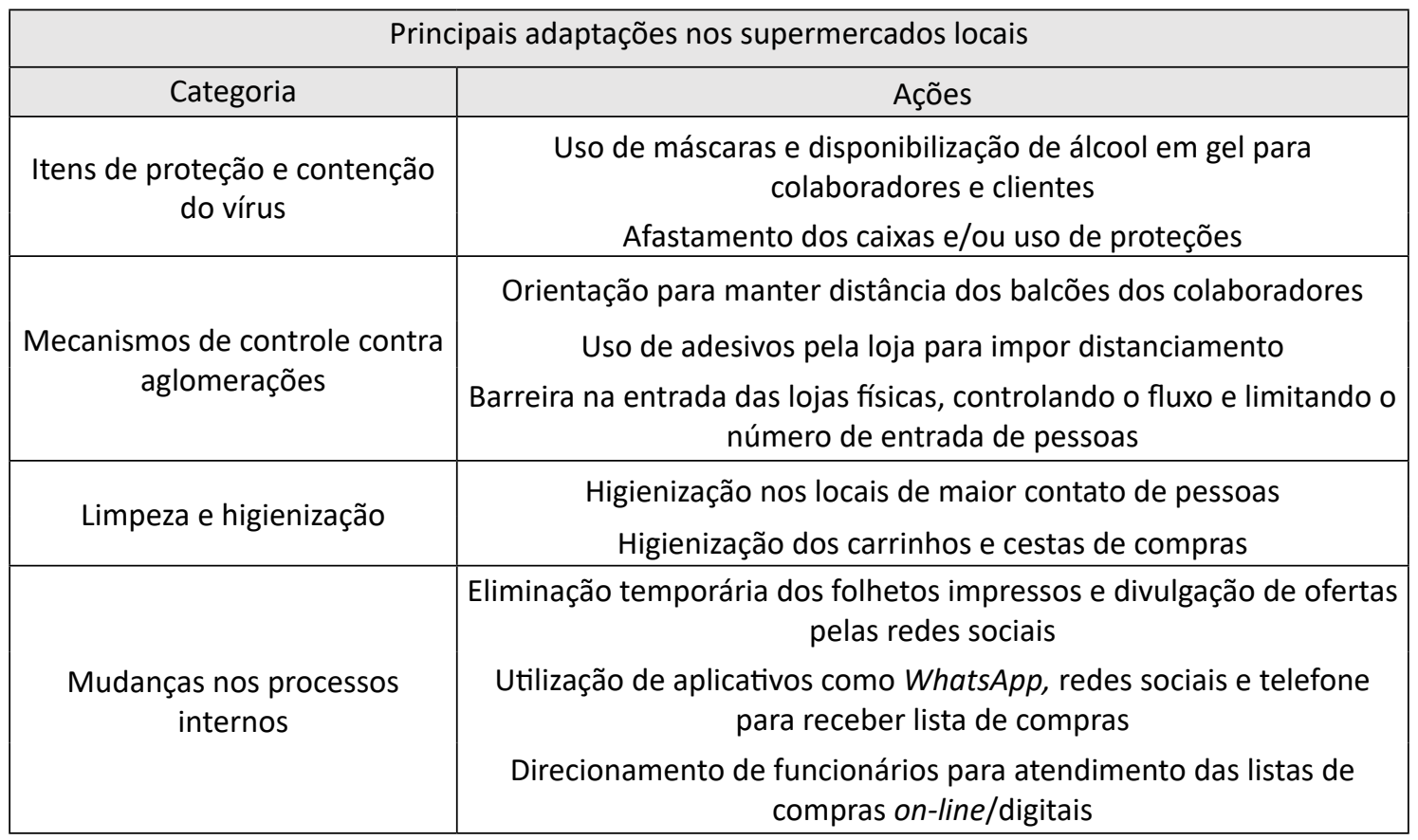

Fonte: Os autores.

As estratégias para adequar os sortimentos, os preços e a distribuição de cada canal devem ser analisadas de modo a gerar competitividade para o supermercado e devem ser estabelecidas de acordo com as necessidades e perfil de seus clientes. Além disso, a estruturação dos processos internos e de mão de obra interna deve ser considerada de modo a atender a esses canais físicos e digitais, e os estímulos ambientais e físicos devem ser ajustados de modo a atingir as vantagens de cada tipo de canal.

\section{CONSIDERAÇÕES FINAIS}

O aceleramento da digitalização e a experiência atual que a sociedade está vivenciando, com as modalidades de teletrabalho e comercialização digital, podem ser uma tendência no mundo pós-pandemia. Além disso, as consequências econômicas que a pandemia irá gerar nos países poderão afetar cadeias de suprimentos internacionais e nacionais, prejudicar a renda de muitas empresas e famílias, influenciar políticas públicas afetando diretamente a sociedade e modificar o foco de muitas marcas e consumidores, que estarão mais preocupados com a segurança.

Todos esses fatores impactam diretamente no comportamento de consumo e as empresas precisam adaptar seus modelos de negócio para se ajustar às novas circunstâncias econômicas e sociais da população. Nesse sentido, a pandemia afetou diretamente no comportamento do consumidor e o setor supermercadista teve de agir rapidamente para entender as novas necessidades e adaptar suas estratégias para assegurar o abastecimento de seus produtos, além de promover a segurança e satisfação de seus clientes. 
Entre as estratégias analisadas por este estudo estão as transformações no ambiente físico com medidas de higienização e limpeza, estratégias multicanais de vendas e, com elas, adaptações na rotina e funções de colaboradores, e adaptações nos meios de divulgação de ofertas. Essas mudanças foram provocadas tanto em âmbito nacional quanto localmente em estabelecimentos de um município do interior de Minas Gerais, permitindo a análise de que o medo e o comportamento dos consumidores, mesmo em localidades em que o vírus se propagou em escalas muito menores, são suficientes para que as empresas comecem a traçar novas estratégias, considerando, inclusive, o mundo pós-pandemia.

Ademais, é importante destacar que planejamentos que considerem uma gestão de risco podem ser importantes para organizações, dos mais variados tamanhos e setores - considerando que mesmo os estabelecimentos que não precisaram parar durante períodos de medidas de fechamento temporário, como os supermercados, tiveram desafios na instauração de mudanças em um curto espaço de tempo. A gestão de risco pode permitir análises de sistemas de produção que se adéquem aos riscos a que sociedade moderna está submetida, como as pandemias e até mesmo cyber ataques, entre outros.

No que diz respeito às tendências e à utilização de canais on-line pelas organizações, o setor supermercadista ainda precisa adotar estratégias de aprimoramento de suas ferramentas, seja por meio do e-commerce, marketplace, seja de ferramentas digitais como aplicativos de comunicação e redes sociais. As estratégias e os processos internos dos estabelecimentos supermercadistas deverão ser analisados com o retorno das atividades normais da sociedade, de forma a permitir maior integração com os novos canais estabelecidos.

Especificamente, o presente estudo teve como objetivo principal analisar como as transformações ocorridas nos hábitos dos consumidores afetaram as estratégias organizacionais no setor supermercadista durante o período de distanciamento social ampliado provocado pela pandemia. Os resultados alcançados podem colaborar para a compreensão do contexto atual pandêmico e em como ele influencia o comportamento do consumidor em cada fase de avanço da propagação do vírus na sociedade.

O cenário brasileiro atual, de enfrentamento à crise sanitária da Covid-19 e de instabilidade política, provoca muitas incertezas em diversos setores econômicos. Nesse contexto, a presente pesquisa contribui para a percepção de que o setor supermercadista tem buscado soluções para adequar suas estratégias organizacionais de forma a cumprir com seu compromisso de abastecimento da sociedade e reduzir as probabilidades de propagação do vírus. Dentro das adaptações realizadas, as medidas de higiene e promoção do distanciamento entre pessoas dentro das lojas físicas se destacam no que tange aos canais de venda off-line. Para os canais on-line, o setor carece de melhorar suas estratégias, no entanto foi possível perceber que o setor adaptou a tecnologia existente dentro de aplicativos populares entre os consumidores do país para enfrentar os desafios atuais.

O questionário aplicado nesta pesquisa foi realizado em apenas um município brasileiro, limitando a abrangência do comportamento do consumidor para outras regiões, ou seja, os fatores culturais regionais do consumidor (CORRÊA; GIANESI, 2019) em outras localidades, podem impactar de diferentes maneiras as adaptações do setor. Buscou-se reduzir os impactos dessa limitação ao cruzar esses resultados com os dados secundários de pesquisas realizadas em âmbito nacional. 
Sugere-se, no entanto, que pesquisas futuras analisem o impacto do comportamento nas adaptações do setor supermercadista com foco no fator cultural regional do consumidor, considerando o contexto de pandemia ou, ainda, analisem as alterações e adaptações nas estratégias com foco na cadeia de abastecimento e nos desafios tanto no fornecimento quanto nas operações de distribuição enfrentadas por esses estabelecimentos. Além disso, a etapa de normalização das atividades não foi analisada neste trabalho devido ao período de distanciamento social em que o país ainda se encontra. Por fim, propõe-se que estudos futuros analisem as alterações e adaptações nas estratégias e nos processos internos do setor após a normalização das atividades no cenário pós-pandemia.

\section{REFERÊNCIAS}

ALMEIDA, M. R. O varejo virtual na realidade do consumidor e lojas físicas no Brasil. Revista Negócios em Projeção, v. 5, n. 2, p. 1-19, 2014.

BRASIL. Congresso Nacional. Lei no 13.979 de 6 de fevereiro de 2020. Diário Oficial [da] República Federativa do Brasil. Brasília, DF, 2020a. Disponível em: http://www.planalto.gov.br/ccivil_03/_Ato20192022/2020/Lei/L13979.htm. Acesso em: 16 jun. 2020.

BRASIL. Congresso Nacional. Medida provisória no 926, de 20 de março de 2020. Diário Oficial [da] República Federativa do Brasil. Brasília, DF, 2020b. Disponível em: http://www.planalto.gov.br/ccivil_03/_ Ato2019-2022/2020/Mpv/mpv926.htm. Acesso em: 16 jun. 2020.

BRASIL. Ministério da Saúde. Painel de casos de doença pelo coronavírus 2019 (COVID-19) no Brasil pelo Ministério da Saúde. Brasília, DF. 2020c. Disponível em: https://covid.saude.gov.br/. Acesso em: 2 jul. 2020.

BRASIL. Ministério da Saúde. Ministério da Saúde declara transmissão comunitária nacional. Notícias Ministério da Saúde. 2020d. Disponível em: https://www.saude.gov.br/noticias/agencia-saude/46568-ministerio-da-saude-declara-transmissao-comunitaria-nacional. Acesso em: 2 jul. 2020.

BRASIL. Congresso Nacional. Lei no 13.982 de 2 de abril de 2020. Diário Oficial [da] República Federativa do Brasil, Brasília, DF, 2020e. Disponível em: http://www.planalto.gov.br/ccivil_03/_ato2019-2022/2020/ lei/l13982.htm. Acesso em: 12 jul. 2020.

BERRY, L. L. et al. Service Safety in the Pandemic Age. Journal of Service Research, First Published, 29 July 2020.

CORRÊA, H. L.; GIANESI, I. G. N. Administração estratégica de serviços: operações para a satisfação do cliente. 2. ed. São Paulo: Atlas, 2019.

FERREIRA, C. Pesquisa quantitativa e qualitativa: perspectivas para o campo da educação. Revista Mosaico, Curitiba, v. 8, n. 2, p. 173-182, 2015.

GAMBARO, F. Consumer Thermomether. Kantar Brasil Insights. 3. ed. 2020. Disponível em: https://br.kantar.com/mercado-e-pol\%C3\%ADtica/sa\%C3\%BAde-e-esporte/2020/thermometer-ed3/. Acesso em: 1o jul. 2020.

GIBOTTI, F. et al. Covid-19: uma visão do comportamento de consumo para supermercados e atacados. GS Ciência do Consumo. 2020a. Disponível em: https://brasil.gs/gspaper/covid-19-o-comportamento-de-consumo-em-supermercados-e-atacados-2/. Acesso em: 21 jun. 2020.

GIBOTTI, F. et al. Covid-19: comportamento de consumo para supermercado e atacados (1a quinzena de abril). GS Ciência do Consumo. 2020b. Disponível em: https://brasil.gs/gspaper/covid19-comportamento-de-consumo-1-quinzena-abril-2020/. Acesso em: 21 jun. 2020.

GIBOTTI, F. et al. Covid-19: comportamento de consumo para supermercado e atacados (2a quinzena de abril). GS Ciência do Consumo. 2020c. Disponível em: https://brasil.gs/gspaper/covid19-comportamento-de-consumo-2-quinzena-abril-2020/. Acesso em: 21 jun. 2020.

GIBOTTI, F. et al. Covid-19: o comportamento do público +60. GS Ciência do Consumo. 2020d. Disponível em: https://brasil.gs/gspaper/covid-19-o-comportamento-de-consumo-em-supermercados-e-atacados/. Acesso em: 25 jun. 2020.

GIBOTTI, F. et al.Comportamentos e expectativas do shopper pós-covid-19. GS Ciência do Consumo. 2020e. Disponível em: https://brasil.gs/gspaper/comportamento-e-expectativas-do-shopper-pos-covid-19/. Acesso em: 25 jun. 2020. 
GIBOTTI, F. et al. Aflições e expectativas Covid-19. GS Ciência do Consumo. 2020f. Disponível em: https:// brasil.gs/gspaper/aflicoes-expectativas-do-varejo-covid-19/. Acesso em: 25 jun. 2020.

GODDARD, E. The impact of Covid-19 on food retail and food service in Canada: Preliminary assessment. Canadian Journal of Agricultural Economics, v. 68, p. 157-161, 2020.

GOULART, R. D. et al. O uso do WhatsApp como ferramenta mercadológica no segmento de supermercados. Revista Navus, Florianópolis, SC, v. 9, n. 3, p. 41-54. 2019.

GS CIÊNCIA DO CONSUMO. Portal Investne: Redes varejistas registram crescimento ate 113 com vendas por WhatsAapp em marco. GS Imprensa. 2020. Disponível em: https://brasil.gs/imprensa/portal-investne-redes-varejistas-registram-crescimento-ate-113-com-vendas-por-whatsapp-em-marco/. Acesso em: 18 jul. 2020.

HALL, M. C. et al. Beyond panic buying: consumption displacement and COVID-19. Journal of Service Management, v. 32, Issue 1, 2020.

HASSAN, T. A. et al. Firm-level Exposure to Epidemic Diseases: Covid-19, SARS, and H1N1. NBER Working Paper 26971, 2020. Disponível em: https://ideas.repec.org/p/nbr/nberwo/26971.html.

HOBBS, J. E. Food supply chains during the Covid-19 pandemic. Canadian Journal of Agricultural Economics, v. 68, p. 171-176, 2020.

KABADAYI, S.; O'CONNOR, G. E.; TUZOVIC, S. Viewpoint: The impact of coronavirus on service ecosystems as service mega-disruptions. Journal of Services Marketing, v. 34, n. 6, 2020.

KANTAR. Consumer Thermomether. Kantar Brasil Insights. 7. ed. 2020a. Disponível em: https://br.kantar. com/mercado-e-pol\%C3\%ADtica/sa\%C3\%BAde-e-esporte/2020/thermometer-ed7/. Acesso em: 10 jul. 2020.

KANTAR. Consumer Thermomether. Kantar Brasil Insights. 9. ed. 2020b. Disponível em: https://br.kantar. com/mercado-e-pol\%C3\%ADtica/sa\%C3\%BAde-e-esporte/2020/thermometer-ed9/. Acesso em: 10 jul. 2020.

KONDUTO; ABCOMM. E-commerce de produtos durante a pandemia da COVID-19. ABCOMM, 2020. Disponível em: https://abcomm.org/Pesquisas/ecommerce-no-covid-konduto-abcomm.pdf.

LAS CASAS, Alexandre Luzzi; LAS CASAS, Jéssica Lora. Marketing de serviços: como criar valores e experiências aos clientes.7. ed. São Paulo: Atlas, 2019.

LAZZARINI, J. C. et al. Uma análise da definição do sortimento nos supermercados brasileiros e sua influência nas vendas. Brazilian Journal of Marketing - BJM; Revista Brasileira de Marketing - ReMark. v. 14, n. 4, 2015.

LEGGETT, R. Qualidade e eficácia podem superar as sensibilidades de preço em meio a preocupações com o coronavírus. Nielsen Inshights, 2020. Disponível em: https://cosmeticinnovation.com.br/qualidade-e-eficacia-podem-superar-as-sensibilidades-de-preco-em-meio-a-preocupacoes-com-o-coronavirus/.

MACHADO, M. D. S.; CRISPIM, S. F. Diferenças no composto varejista de lojas físicas e virtual da mesma rede. Revista de Administração Contemporânea-RAC, v. 21, p. 203-226, 2017.

MARTINS, R. A O método do estudo de caso na engenharia de produção. In: MIGUEL, P. A. C. Metodologia de pesquisa em engenharia de produção e gestão de operações. Rio de Janeiro: Elsevier, 2012. p. 47-63. Cap. 3.

MARIOTTI, J. E-commerce de alimentos e bebidas: uma mina de ouro quase inexplorada. Nova Varejo. 2020. Disponível em: https://www.consumidormoderno.com.br/2020/02/11/e-commerce-alimentos-bebidas-brasil/. Acesso em: 20 jul. 2020.

NEWTRADE. Marketplace ganha espaço e muda perfil das entregas. Newtrade O Portal do Comércio, 2020a. Disponível em: https://newtrade.com.br/tecnologia/marketplace-ganha-espaco-e-muda-perfil-das-entregas/.Acesso em: 10 jul. 2020.

NEWTRADE. Brasileiro pretende manter nível reduzido de consumo no pós-pandemia, mostra pesquisa. Newtrade Economia. 2020b. Disponível em: https://newtrade.com.br/economia/brasileiro-pretende-manter-nivel-reduzido-de-consumo-no-pos-pandemia-mostra-pesquisa/. Acesso em: 6 jul. 2020.

NIELSEN. As seis etapas nielsen sobre o comportamento do consumidor perante a preocupação do COVID-19. Nielsen, 2020a. Disponível em: https://www.nielsen.com/pt/pt/insights/article/2020/seis-etapas-nielsen-comportamento-consumidor-perante-covid-19/7/. Acesso em: 20 jun. 2020.

NIELSEN. Como o brasileiro se prepara para vida restritiva imposta pela COVID-19. Nielsen, 2020b. Disponivel em: https://www.nielsen.com/br/pt/insights/article/2020/como-o-brasileiro-se-prepara-para-vida-restritiva-imposta-pela-covid-19/. Acesso em: 23 jun. 2020. 
NIELSEN.COVID-19 atingirá mais os consumidores de baixa renda na América Latina. Nielsen, 2020c. Disponivel em: https://www.nielsen.com/br/pt/insights/article/2020/covid-19-atingira-mais-os-consumidores-de-baixa-renda-na-america-latina/. Acesso em: 7 jun. 2020.

NIELSEN.COVID-19: O catalisador inesperado para a adoção da tecnologia. Nielsen, 2020d. Disponivel em: https://www.nielsen.com/br/pt/insights/article/2020/covid-19-o-catalisador-inesperado-para-a-adocao-da-tecnologia/. Acesso em: 6 jul. 2020.

OXFORD ECONOMICS. Global economic prospects: World GDP to fall $2.8 \%$ in 2020 , exceeding financial crisis toll. Oxford Economics, 2020. Disponível em: https://resources.oxfordeconomics.com/world-gdp-to-fall-2.8-in-2020-exceeding-financial-crisis-toll.

RIBEIRO, L. P. Supermercados: a nova fronteira do varejo on-line. E-commerce Brasil, 2019. Disponível em: https://www.ecommercebrasil.com.br/artigos/supermercados-a-nova-fronteira-do-varejo-online/. Acesso em: 15 jul. 2020.

REZENDE, A. A.; MARCELINO, J. A.; MIYAJI, M. A reinvenção das vendas: as estratégias das empresas brasileiras para gerar receitas na pandemia de covid-19. Boletim de Conjuntura (Boca), v. 2, n. 6, 2020.

SEBRAE. Serviço Brasileiro de Apoio às Micro e Pequenas Empresas. Como montar um supermercado, mercearia e similares. Sebrae Empreendedorismo. 2016. Disponível em: https://www.sebrae.com.br/ sites/PortalSebrae/ufs/mg/artigos/como-abrir-um-supermercado-mercearia-e-similares-em-minas-gerais,a04d6484b071b410VgnVCM1000003b74010aRCRD.

SÖDERLUND, M. Employee norm-violations in the service encounter during the corona pandemic and their impact on customer satisfaction. Journal of Retailing and Consumer Services, v. 57, 2020.

TURRIONI, J. B.; MELLO, C. H. P. Metodologia de pesquisa em engenharia de produção. Universidade Federal de Itajubá, 2012.

VALENTE, J. WhatsApp é principal fonte de informação do brasileiro, diz pesquisa. Agência Brasil. 2019. Disponível em: https://agenciabrasil.ebc.com.br/geral/noticia/2019-12/whatsapp-e-principal-fonte-de-informacao-do-brasileiro-diz-pesquisa. Acesso em: 20 jul. 2020.

WHO. World health ORGANIZATION. WHO Director-General's opening remarks at the media briefing on COVID-19 - 11 March 2020. WHO. 2020. 